\title{
Regional Distribution of White Matter Hyperintensities in Vascular Dementia, Alzheimer's Disease and Healthy Aging
}

\author{
L. Gootjes ${ }^{a, c}$ S.J. Teipela Y. Zebuhr ${ }^{a}$ R. Schwarz ${ }^{a} \quad$ G. Leinsinger ${ }^{b}$ \\ P. Scheltens ${ }^{d}$ H.-J. Möllera H. Hampela \\ aAlzheimer Memorial Center and Geriatric Psychiatry Branch, Dementia and Neuroimaging Section, \\ Department of Psychiatry, and bepartment of Radiology, Ludwig Maximilian University, Munich, Germany; \\ 'Department of Clinical Neuropsychology, Vrije Universiteit Amsterdam, and dDepartment of Neurology, \\ Alzheimer Center, Vrije Universiteit Medical Center, Amsterdam, The Netherlands
}

\author{
Key Words \\ Magnetic resonance imaging - White matter • \\ Neuropsychology
}

\begin{abstract}
Background: White matter hyperintensities (WMH) on MRI scans indicate lesions of the subcortical fiber system. The regional distribution of WMH may be related to their pathophysiology and clinical effect in vascular dementia (VaD), Alzheimer's disease (AD) and healthy aging. Methods: Regional WMH volumes were measured in MRI scans of $20 \mathrm{VaD}$ patients, $25 \mathrm{AD}$ patients and 22 healthy elderly subjects using FLAIR sequences and surface reconstructions from a three-dimensional MRI sequence. Results: The intraclass correlation coefficient for interrater reliability of WMH volume measurements ranged between 0.99 in the frontal and 0.72 in the occipital lobe. For each cerebral lobe, the WMH index, i.e. WMH volume divided by lobar volume, was highest in $\mathrm{VaD}$ and lowest in healthy controls. Within each group, the WMH index was higher in frontal and parietal lobes than in occipital and temporal lobes. Total WMH index and $\mathrm{WMH}$ indices in the frontal lobe correlated sig-
\end{abstract}

nificantly with the MMSE score in VaD. Category fluency correlated with the frontal lobe WMH index in AD, while drawing performance correlated with parietal and temporal lobe WMH indices in VaD. Conclusions: A similar regional distribution of $\mathrm{WMH}$ between the three groups suggests a common (vascular) pathogenic factor leading to $\mathrm{WMH}$ in patients and controls. Our findings underscore the potential of regional WMH volumetry to determine correlations between subcortical pathology and cognitive impairment.

Copyright $@ 2004$ S. Karger AG, Basel

\section{Introduction}

Clinicopathological studies indicate that diffuse hyperintensities in the deep subcortical white matter (so-called white matter hyperintensities, $\mathrm{WMH}$ ) on $\mathrm{T}_{2}$-weighted magnetic resonance imaging (MRI) scans represent ischemic damage of the subcortical fiber system [1-3]. Diffuse WMH are most prevalent in vascular dementia (VaD) [4] but are also reported in $27-92 \%$ of the elderly population $[5,6]$. An increase in WMH in patients with Alzheimer's disease (AD) compared to age-matched healthy elderly

\begin{tabular}{ll}
\hline KARGER & ( ) 2004 S. Karger AG, Basel \\
1420-8008/04/0182-0180\$21.00/0 \\
$\begin{array}{l}\text { Fax+4161306 12 34 } \\
\begin{array}{l}\text { E-Mail karger@karger.ch } \\
\text { www.karger.com }\end{array}\end{array}$ & $\begin{array}{l}\text { Accessible online at: } \\
\text { www.karger.com/dem }\end{array}$
\end{tabular}

P. Scheltens, MD, PhD

Alzheimer Center and Department of Neurology

VU Medical Center, PO Box 7057

NL-1007 MB Amsterdam (The Netherlands)

Tel. +31 20 4440742, Fax +31 20 4440715, E-Mail p.scheltens@vumc.nl 
recruited among spouses and friends of patients with dementia. The Dutch controls completed the CAMCOG, the MMSE, the MADRS and the CUSPAD. German controls were healthy volunteers recruited from elderly members of a local parish. The German controls completed the cognitive battery of the Consortium to Establish a Registry for Alzheimer's Disease (CERAD), the HAMD and the SIDAM. Exclusion criteria were history or presence of depression, dementia or mild cognitive impairment and history or presence of any other significant neurological, physical or psychiatric disorder including drug and alcohol misuse.

Two Dutch controls had a history of hypertension but showed normal values after treatment; German controls had no history of hypertension and had normal blood pressure at the time of clinical examination. Four German and 5 Dutch VaD patients had a history of hypertension. Two German and 2 Dutch AD patients had a history of hypertension but showed normal values after treatment.

The reliability of WMH measurement was evaluated in an independent group of 10 German subjects. This group comprised 2 healthy elderly subjects, 6 patients with clinical probable AD and 2 patients with mixed dementia (mean age \pm SD was $74.9 \pm 8.4$; female-to-male ratio was $7 / 3$ ).

Informed written consent was asked and received from all patients and healthy subjects. Both ethical committees of the Ludwig Maximilian University, Munich, Germany, and the Vrije Universiteit Amsterdam, The Netherlands, approved of the study.

\section{Magnetic Resonance Imaging}

MRI examinations were performed on a 1.5-tesla Siemens Magnetom Vision MRI scanner for the German subjects and on a 1.0tesla Siemens Magnetom Impact MRI scanner for the Dutch subjects (both scanners from Siemens, Erlangen, Germany). All subjects had a volumetric $\mathrm{T}_{1}$-weighted sagittally oriented MRI sequence (for German subjects: $\mathrm{TR}=11.6 \mathrm{~ms}, \mathrm{TE}=4.9 \mathrm{~ms}$, resolution $=0.94$ by 0.94 by $1.2 \mathrm{~mm}$; for Dutch subjects: $\mathrm{TR}=15 \mathrm{~ms}, \mathrm{TE}=7 \mathrm{~ms}$, resolution $=$ 0.98 by 0.98 by $1.0 \mathrm{~mm}$ ). Some scans were done with an inplane resolution of $0.5 \mathrm{~mm}$ by $0.5 \mathrm{~mm}$; these scans were blurred to a resolution of 0.94 by $0.94 \mathrm{~mm}$ with trilinear interpolation using Analyze AVW software (Mayo Foundation, Rochester, Minn., USA). Additionally, an axially oriented fast FLAIR sequence (for German subjects: $\mathrm{TR}=9,000 \mathrm{~ms}, \mathrm{TE}=110 \mathrm{~ms}$, resolution $=0.94$ by 0.94 by $6 \mathrm{~mm}$; for Dutch subjects: $\mathrm{TR}=9,000 \mathrm{~ms}, \mathrm{TE}=105 \mathrm{~ms}$, resolution $=$ 0.98 by 0.98 by $5 \mathrm{~mm}$ ) was obtained.

\section{Regional Distribution of WMH}

An anatomical template was made to identify the borders of frontal, parietal, temporal and occipital lobes, using the volumetric $\mathrm{T}_{1^{-}}$ weighted sequence and Analyze AVW software (Mayo Foundation) as previously described [30]. After editing the brain volume from all nonbrain tissue, the anatomical borders of the 4 lobes were determined on the surface reconstruction of the brain, using anatomical landmarks and simple geometrical constructions [30]. The frontalparietal border was defined by the sulcus centralis, and the frontaltemporal border was determined by the sulcus lateralis. The parietooccipital, the temporo-occipital and the parietotemporal borders were defined by a geometrical construction (fig. 1). The anatomical template was reconstructed in the orientation and resolution of the corresponding FLAIR weighted axial slices, using an affine transformation (AIR 3.08) [31]. WMH volumes were measured on the FLAIR sequence. The lesions were semiautomatically traced, using a region growing algorithm based on pixel intensity (fig. 1).
Lesions were manually edited, if visual inspection suggested inconsistencies of the automated segmentation. The number of voxels within each lesion was summed automatically and multiplied by the voxel size to obtain absolute values $\left(\mathrm{mm}^{3}\right)$ for the lesions. The outer borders of the lobes were easily identified on the axial FLAIR sequence by comparing with the corresponding anatomical template. Internal lobar boundaries were determined according to welldescribed criteria (Psychiatry Research, Neuroimaging Section, accepted). The sum of lesions within each lobe gave the absolute WMH load for each lobe. Lesions that crossed a lobar border were divided along this border, and each part was attributed to the corresponding lobe. Lobar WMH indices were calculated by dividing lobar WMH volume by lobar volume. The total WMH index was calculated by dividing the sum of WMH volumes across lobes by total brain volume. Total brain volume and lobar volumes were measured on the $\mathrm{T}_{1}$-weighted volumetric scans according to a well-described method (Psychiatry Research, Neuroimaging Section, accepted). All WMH indices are expressed as percent $\times 10^{-2}$ of lobar volume to simplify reporting of numbers.

\section{Neuropsychological Examination}

Cognitive performance was investigated in a subgroup of $17 \mathrm{AD}$ and $6 \mathrm{VaD}$ patients from the German center and a subgroup of 5 $\mathrm{VaD}$ patients from the Dutch center. German patients were tested with the cognitive battery of the CERAD [32], Dutch patients were tested using the cognitive battery of the Alzheimer's Disease Assessment Scale (ADAS) [33]. In addition to the ADAS, delayed 10-word list recall and animal category verbal fluency were tested in Dutch patients. To account for difference in the scoring of the CERAD and the ADAS, scoring criteria of the CERAD were used for both German and Dutch patients. To account for the different number of items in the recognition and the naming task between German and Dutch patients, percentage scores were calculated for these tasks by dividing the number of correct responses by the maximum score.

\section{Statistics}

WMH indices were not normally distributed within groups, as shown by the Schapiro-Wilks test and visual inspection of histograms. To control for potential effects of age and center, betweengroup differences in WMH load were assessed using univariate analysis of covariance with ranked regional WMH indices as dependent variables and age, center and diagnosis as predictors. The regional distribution of lobar WMH indices within each group was tested using the Wilcoxon signed-ranks test. Correlations between WMH indices and neuropsychological measures and age were controlled for confounding effects of center, using partial correlation on the ranktransformed $\mathrm{WMH}$ indices.

To determine the reliability of WMH measurements by different raters, the intraclass correlation coefficient (ICC) was determined by measuring $\mathrm{WMH}$ of 10 subjects by 2 independent investigators twice (L.G. and Y.Z.), blinded to clinical diagnosis.

\section{Results}

As shown in table 2, after accounting for the effects of age and center, total and regional WMH indices were significantly higher in $\mathrm{VaD}$ patients than in healthy controls. Furthermore, total and regional WMH indices were sig- 
Fig. 1. Surface map for tracing of lobar borders and axial FLAIR images with regional segmentation. The letters A, B, C, D, E, H and $X$ denote the intersections of lines or reference points. A is the endpoint of the ascending branch of the sulcus lateralis. $\mathrm{B}$ is at the parieto-occipital sulcus. Through $\mathrm{C}$, the center of the line $\mathrm{AB}$, a line $\mathrm{CH}$ was drawn perpendicularly to the line $\mathrm{AB}$. $\mathrm{D}$ was determined along the line $\mathrm{CH}$, where it intersects the tissue/nontissue border of the brain. The midpoint along line $\mathrm{CD}$ is denoted $\mathrm{X}$, from which a line was drawn to $\mathrm{A}$ and to $\mathrm{B}$. FLAIR images with semiautomatically traced WMH are overlaid with the corresponding anatomical template indicating different regions of the brain (shown with different line patterns, arrowheads are indicating borders between lobes).

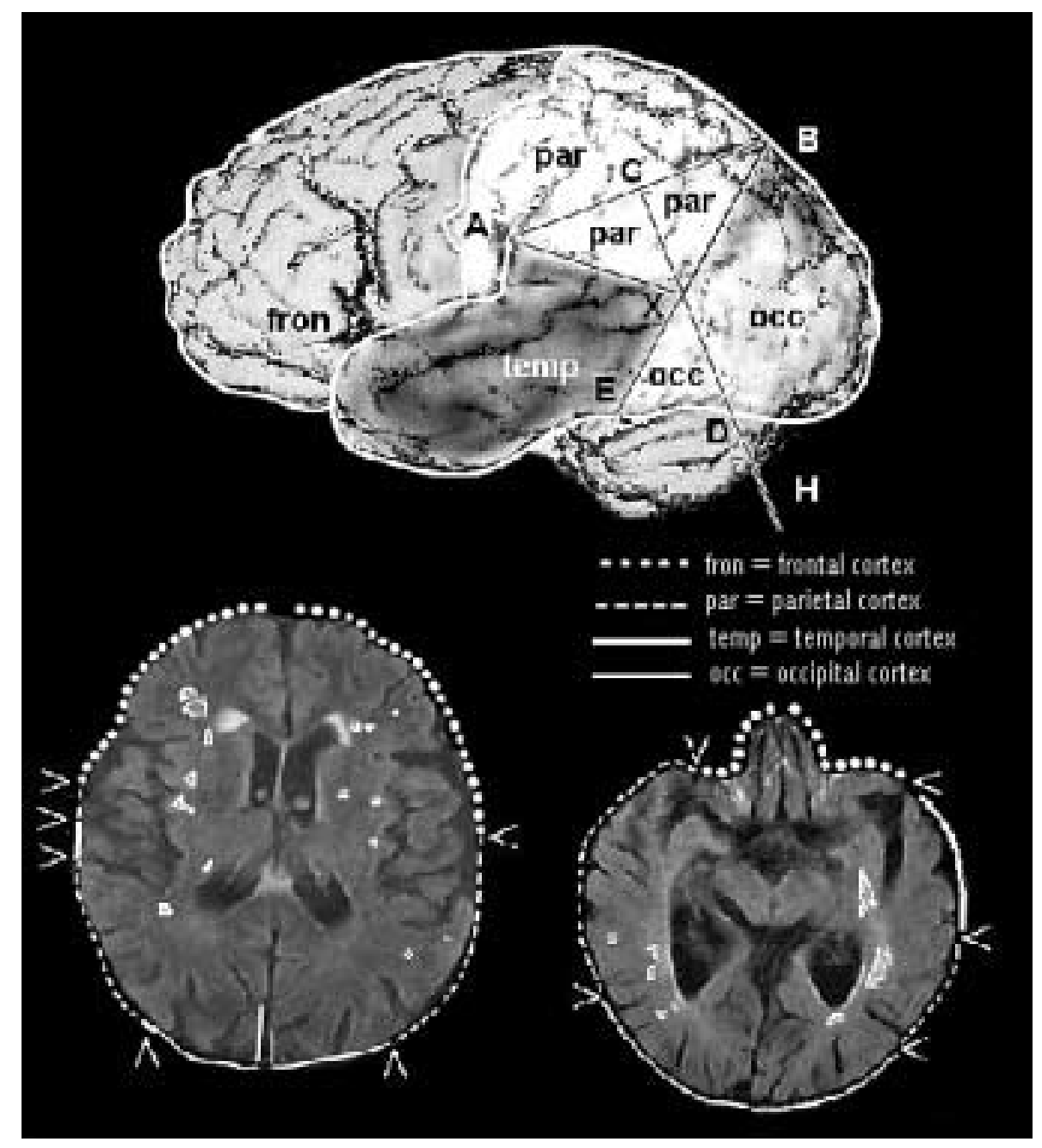

Table 2. Regional WMH indices in percent $\times 10^{-2}$ of respective lobe volume

\begin{tabular}{|c|c|c|c|c|c|c|c|c|}
\hline & \multicolumn{2}{|c|}{ Comparison subjects } & \multicolumn{2}{|c|}{ AD patients } & \multicolumn{2}{|c|}{ VaD patients } & \multicolumn{2}{|c|}{$\operatorname{Ancova}($ d.f. $=2,62)$} \\
\hline & mean & SD & mean & SD & mean & $\mathrm{SD}$ & $\mathrm{F}$ & $\mathrm{p}$ \\
\hline Total & 1.55 & 2.12 & 3.77 & 3.96 & 24.53 & 28.19 & 13.4 & $<0.001^{\mathrm{a}, \mathrm{b}}$ \\
\hline Frontal & 3.05 & 4.10 & 6.80 & 9.92 & 45.84 & 55.43 & 7.1 & $<0.002^{\mathrm{a}, \mathrm{b}}$ \\
\hline Parietal & 2.87 & 5.15 & 7.02 & 5.68 & 48.57 & 56.16 & 18.8 & $<0.001^{\mathrm{a}, \mathrm{b}, \mathrm{c}}$ \\
\hline Temporal & 0.71 & 1.01 & 1.65 & 3.98 & 4.97 & 6.16 & 6.7 & $<0.002^{\mathrm{a}, \mathrm{b}}$ \\
\hline Occipital & 0.58 & 1.14 & 3.34 & 5.99 & 8.99 & 13.16 & 4.4 & $<0.02^{\mathrm{a}, \mathrm{c}}$ \\
\hline
\end{tabular}

Ancova = Analysis of covariance on rank-transformed values of WMH indices: overall group effect, covariates were age and center.

a The WMH index was significantly higher in VaD than in controls (Ancova; d.f. =1, 38; with age and center as covariates, $\mathrm{p}<0.02$ ).

b The WMH index was significantly higher in $\mathrm{VaD}$ than in $\mathrm{AD}$ (Ancova; d.f. = 1, 41; with age and center as covariates, $\mathrm{p}<0.001$ ).

c The WMH index was significantly higher in $\mathrm{AD}$ than in controls (Ancova; d.f. =1, 43; with age and center as covariates, $\mathrm{p}<0.03$ ). 


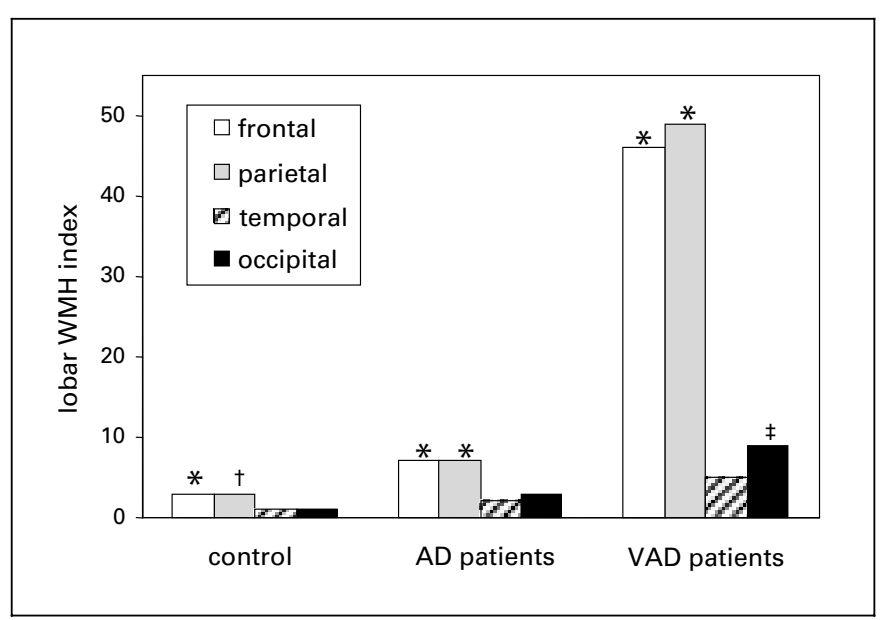

Fig. 2. Regional distribution of WMH indices. Lobar $\mathrm{WMH}$ index = WMH volume/lobar volume $\times 10^{4} ; *=$ higher compared to temporal $(\mathrm{p}<0.001)$ and occipital WMH indices $(\mathrm{p}<0.05) ;{ }^{\dagger}=$ higher compared to occipital WMH index $(\mathrm{p}<0.001) ;{ }^{\neq}=$higher compared to temporal WMH index $(\mathrm{p}<0.05)$.

nificantly higher in $\mathrm{VaD}$ than in $\mathrm{AD}$ patients, with the exception of the occipital WMH index. In the AD group, parietal and occipital WMH indices were significantly higher compared to controls. Using absolute WMH volumes instead of WMH indices did not alter the significance of these effects.

A regional analysis of WMH variations within each group showed that WMH indices were generally higher in the frontal and parietal lobes than in the temporal and occipital lobes (fig. 2). A similar analysis with absolute WMH volumes showed more WMH in the frontal lobe than in the parietal lobe, and higher $\mathrm{WMH}$ volumes in the parietal lobe than in the temporal and occipital lobes ( $\mathrm{p}<$ 0.05 for all comparisons).

In the VaD group, the total WMH index and WMH index of the frontal lobe were correlated with the MMSE score, including control for a potential difference between the centers $(\mathrm{r}=-0.53, \mathrm{p}<0.01$, and $\mathrm{r}=-0.47, \mathrm{p}<0.001$, respectively; fig. 3a and b). Parietal and temporal WMH indices were significantly correlated with drawing $(\mathrm{r}=$ $0.66, p<0.05$, and $r=0.63, p<0.05$, respectively; fig. $3 c$ ). In the $\mathrm{AD}$ group, there were no significant correlations between MMSE scores and total or regional WMH indices ( $\mathrm{r}$ between -0.13 and $0.25, \mathrm{p}>0.24$ ). Verbal category fluency was correlated with the frontal lobe $\mathrm{WMH}$ index $(r=0.51, p<0.05$; fig. $3 d)$. The significance of these correlations remained unchanged when using absolute WMH volumes. There were no significant correlations between regional WMH indices and naming, verbal learning, recall or recognition in the $\mathrm{AD}$ and $\mathrm{VaD}$ groups.

Total WMH index and regional WMH indices in the frontal, parietal and occipital lobes were positively correlated with age in the $\mathrm{AD}$ group when controlling for center $(\mathrm{r}=0.63, \mathrm{p}<0.001 ; \mathrm{r}=0.48, \mathrm{p}<0.05 ; \mathrm{r}=0.52, \mathrm{p}<0.01$; $\mathrm{r}=0.44, \mathrm{p}<0.05$, respectively). Total and parietal $\mathrm{WMH}$ were significantly correlated with age in the control group when controlling for center $(\mathrm{r}=0.45, \mathrm{p}<0.05$, and $\mathrm{r}=0.64, \mathrm{p}<0.01$, respectively). WMH indices did not correlate with age in the $\mathrm{VaD}$ group. Correlations with age remained unchanged for absolute $\mathrm{WMH}$ volumes.

The ICC for measurements of the total WMH index was 0.996 . The ICC for measurements of regional WMH indices was 0.99 in the frontal lobe, 0.81 in the parietal lobe, 0.998 in the temporal lobe and 0.72 in the occipital lobe.

\section{Discussion}

In the present study, we used a new MRI-based method to measure regional WMH load. We found that WMH indices, i.e. WMH volume normalized to lobar volume, were more pronounced in $\mathrm{VaD}$ patients than in $\mathrm{AD}$ patients and healthy controls. The distribution of WMH across cerebral lobes was similar between groups, with frontal and parietal lobes showing the highest and occipital and temporal lobes showing the lowest WMH load. The WMH indices correlated with age in healthy controls and $\mathrm{AD}$ patients, but not in $\mathrm{VaD}$ patients. Dementia severity correlated with $\mathrm{WMH}$ indices in $\mathrm{VaD}$, but not in AD patients. There were correlations between domainspecific cognitive impairments and regional WMH indices in $\mathrm{AD}$ and $\mathrm{VaD}$ patients. To assure that the effects in $\mathrm{WMH}$ indices were due to $\mathrm{WMH}$ changes and not to changes in lobar volume, all analyses were repeated with absolute WMH volumes.

One improvement of this study compared to earlier studies is the use of a standardized protocol to quantitatively assess regional WMH load. Although several scales exist for visual rating of WMH on MRI [34, 35], only few of them include regional lobar distribution of WMH [14, 15, 36, 37]. Few methods were developed that provide quantitative measures to examine WMH load on MRI, and none of these examined regional WMH volumes [10, $18,19,38]$. Interrater reliability for the measurement of total WMH load with an ICC of 0.99 in our study compares to previous quantitative methods with ICC ranging from 0.97 [18] to 0.99 [19]. The ICC for regional WMH in 


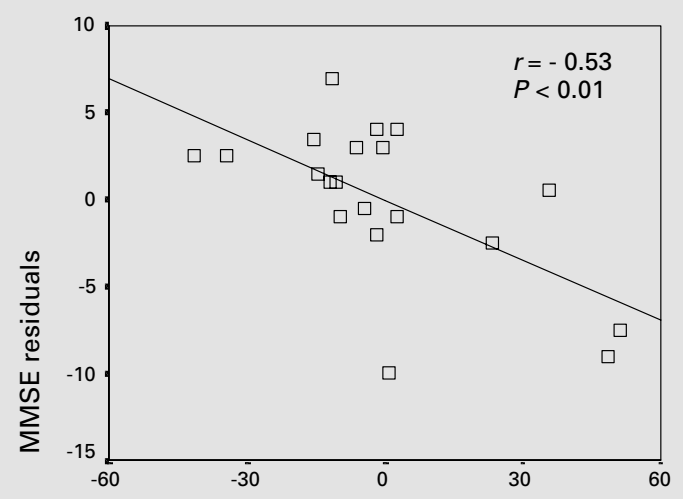

a total WMH density residuals

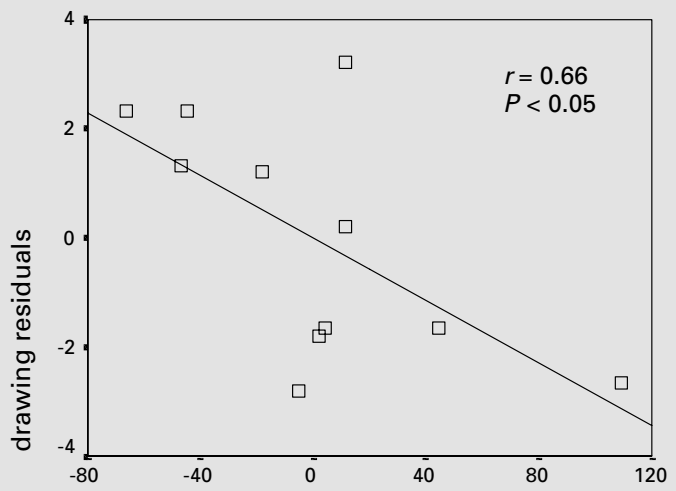

c parietal WMH density residuals

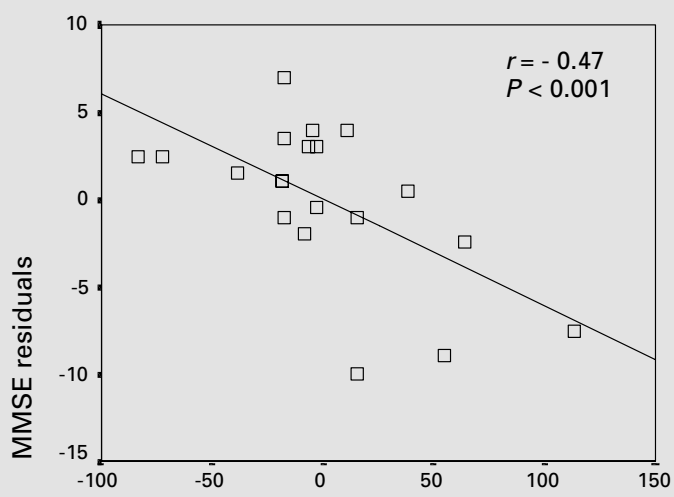

b frontal WMH density residuals

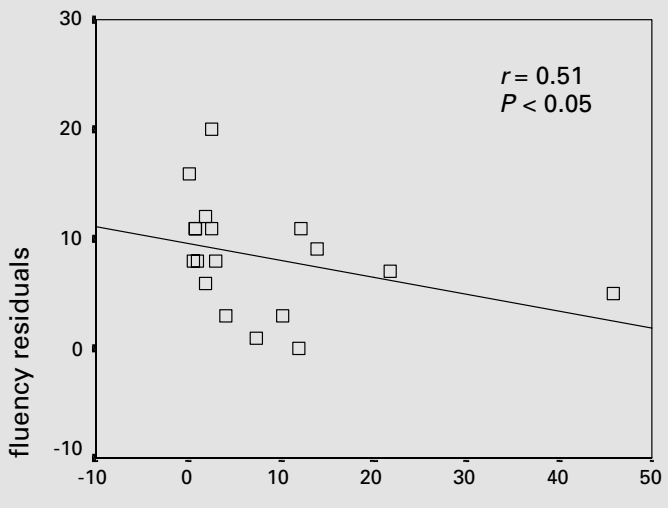

d frontal WMH density residuals

Fig. 3. Cognitive measures and $W M H$ indices in $\mathrm{VaD}$ and $\mathrm{AD}$. Scatter plot of residuals of MMSE score and total (a) and frontal (b) WMH indices controlled for center in the VaD group, of drawing score and parietal WMH index controlled for center in the $\mathrm{VaD}$ group (c) and of fluency score and frontal WMH index controlled for center in the AD group (d).

our study ranged from 0.99 for the frontal lobe to 0.72 for the occipital lobe. To our knowledge there are no previous reports on the interrater reliability of regional WMH measurements. Our method is based on a recently reported segmentation technique to generate an anatomical template for subsequent lesion allocation [30]. The frontal lobe is segmented with reference to anatomical landmarks only, whereas the other lobes are segmented by a combination of anatomical landmarks and a geometrical construction. This may, at least in part, account for the differences in measurement accuracy of WMH across lobes.

Higher $\mathrm{WMH}$ indices in $\mathrm{VaD}$ patients compared to $\mathrm{AD}$ patients and healthy controls, even after controlling for age and center effects, are consistent with previous studies [4, 39]. Parietal and occipital, but not total WMH indices were significantly increased in AD patients compared to healthy controls. This suggests that in AD certain regions are more strongly involved in white matter pathology than others. Such a region-specific WMH increase may be overlooked when only total WMH load is examined. This may explain controversial findings on total WMH load in AD from earlier studies [4, 7, 8, 40].

Regional distribution of WMH indices across lobes was similar between groups. WMH indices were higher in the frontal and parietal lobes than in the occipital and temporal lobes in the demented patients and the healthy controls. Earlier studies described a strong involvement of the frontal and/or parietal lobes in demented patients and healthy elderly subjects using semiquantitative rating scales $[4,6,15,40,41]$. It has been suggested that over- 
representation of the frontal and parietal lobes on axial slices might explain these findings [40]. Consistent with this notion, the absolute frontal WMH volume was highest compared to all other lobes in all groups. But even after normalization to lobar volumes, WMH load was higher in frontal and parietal than in temporal and occipital lobes. Findings from other imaging modalities also suggest that subcortical lesions may be most predominant in the frontal lobe. In computer-assisted tomography scans, leukoaraiosis was predominantly localized in the frontal region in mildly to moderately demented VaD patients, and only with severe dementia was leukoaraiosis more diffusely distributed throughout the brain [42]. Frontal leukoaraiosis correlated with reduced frontal lobe cerebral blood flow in mildly to moderately demented $\mathrm{VaD}$ patients [42]. In diffusion-weighted MRI of $\mathrm{VaD}$ patients the anterior region, particularly the frontal lobe, exhibited more abnormalities in water diffusion than the posterior regions of the brain [43]. Several neuropathological studies found chronic ischemic lesions predominantely in the frontal lobes and/or parietal lobes [24-26, 44, 45] suggesting an increased susceptibility of these lobes for white matter pathology.

In our $\mathrm{VaD}$ patients, dementia severity as measured by MMSE correlated with total and frontal lobe WMH indices. Furthermore, in a subgroup of the $\mathrm{VaD}$ patients measures of drawing performance were correlated with parietal and temporal lobe WMH indices. This location agrees with a large range of neuropsychological studies on patients with impaired drawing performance due to focal cerebral lesions in the bilateral or right parietal lobe [46]. There were no correlations between measures of episodic or semantic memory and regional WMH load. Similarly, Cohen et al. [47] reported correlations of global WMH load with visual-construction and executive-function measures, but not with measures of memory and verbal function in $24 \mathrm{VaD}$ patients. This study, however, did not assess regional WMH load. There were no correlations between MMSE score and total and regional WMH in our AD patients, consistent with other studies [13, 48]. This suggests that either WMH in AD have not the same cognitive significance as in $\mathrm{VaD}$ or that $\mathrm{AD}$ pathology obscures the effect of $\mathrm{WMH}$ on cognition in $\mathrm{AD}$. In AD patients without cerebrovascular disease, the main reason for cognitive impairment is AD-specific cortical pathology and WMH may only contribute to a lesser degree to the cognitive dysfunction.

In a subgroup of AD patients verbal category fluency correlated with the frontal lobe $\mathrm{WMH}$ index. Verbal fluency is a semantic function, involving speed of mental processing and attention, and relays on prefrontal lobe functional integrity [49]. It has been found that $\mathrm{WMH}$ load, especially in the anterior region, is strongly correlated with verbal fluency scores in patients with cerebrovascular disease and stroke [50] and that WMH in healthy elderly subjects shows a strong correlation with performance of frontal lobe functions [10, 12]. However, these findings should be regarded as preliminary, because the number of patients in each group was small.

The similar regional distribution of $\mathrm{WMH}$ in $\mathrm{VaD}, \mathrm{AD}$ and healthy aging suggests that these conditions might share a common pathologic factor for the occurrence of WMH. WMH in the AD and the control group may reflect vascular comorbidity. Indeed, white matter pathology in AD has been linked to ischemic changes [44] that are superimposed on the AD-specific pathology. An agerelated increase in vascular comorbidity may underlie the significant correlation between age and total WMH load in $\mathrm{AD}$ patients and controls found in our and previous studies [48, 51]. In contrast, disease-specific vascular pathology would by far exceed an age-related increase in vascular comorbidity in $\mathrm{VaD}$ patients, thereby masking correlations between age and $\mathrm{WMH}$ load.

In the present study, we investigated healthy elderly controls as well as demented patients with relatively low cardiovascular comorbidity, such as hypertension or diabetes. Therefore, our results represent the effects of healthy aging, pure $\mathrm{AD}$ and pure $\mathrm{VaD}$ on regional subcortical lesions. For the same reason, however, one has to be careful in conferring our findings on the general elderly population, which has a much higher prevalence of cardiovascular comorbidity.

Our findings do underscore the potential of regional WMH volumetry to determine functional consequences of subcortical pathology in different disease conditions. We propose to use regional WMH volumetry in future studies on the general elderly population.

\section{Acknowledgements}

Part of this work was supported by grants of Eisai, Frankfurt, and Pfizer, Karlsruhe, Germany (to H.H. and S.J.T.), of Pharmacia GmbH, Erlangen, Germany (to H.H. and S.J.T.), of the Medical Faculty of the Ludwig Maximilian University, Munich, Germany (to S.J.T.), of the Hirnliga e.V., Nürmbrecht, Germany (to S.J.T. and H.H.), of the Netherlands Organization for Scientific Research and of the Foundation 'De Drie Lichten', The Netherlands (to L.G.). Part of the presented material originates from the doctoral thesis of Y.Z. (Ludwig Maximilian University, Munich, Germany; in preparation).
186

Dement Geriatr Cogn Disord 2004;18:180-188
Gootjes/Teipel/Zebuhr/Schwarz/

Leinsinger/Scheltens/Möller/Hampel 
1 Awad IA, Spetzler RF, Hodak JA, Awad CA Carey R: Incidental subcortical lesions identified on magnetic resonance imaging in the elderly. I. Correlations with age and cerebrovascular risk factors. Stroke 1986;17:10841089.

2 Fazekas F, Schmidt R, Kleinert R, Kapeller P, Roob G, Flooh E: The spectrum of age-associated brain abnormalities: Their measurement and histopathological correlates. J Neural Transm Suppl 1998;53:31-39.

3 Scheltens P, Barkhof F, Leys D, Wolters EC, Ravid R, Kamphorst W: Histopathologic correlates of white matter changes on MRI in Alzheimer's disease and normal aging. Neurology 1995;45:883-888.

4 Barber R, Scheltens P, Gholkar A, Ballard C, McKeith I, Ince P, et al: White matter lesions on magnetic resonance imaging in dementia with Lewy bodies, Alzheimer's disease, vascular dementia, and normal aging. J Neurol Neurosurg Psychiatry 1999;67:66-72.

5 Breteler MM, van Swieten JC, Bots ML, Grobbee DE, Claus JJ, van den Hout JH, et al: Cerebral white matter lesions, vascular risk factors, and cognitive function in a population-based study: The Rotterdam Study. Neurology 1994; 44:1246-1252.

6 de Leeuw FE, de Groot JC, Achten E, Oudkerk M, Ramos LM, Heijboer R, et al: Prevalence of cerebral white matter lesions in elderly people: A population based magnetic resonance imaging study. The Rotterdam Scan Study. J Neurol Neurosurg Psychiatry 2001;70:9-14.

7 Erkinjuntti T, Gao F, Lee DH, Eliasziw M, Merskey H, Hachinski V: Lack of difference in brain hyperintensities between patients with early Alzheimer's disease and control subjects. Arch Neurol 1994;51:260-268.

8 Fazekas F, Kapeller P, Schmidt R, Offenbacher H, Payer F, Fazekas G: The relation of cerebral magnetic resonance signal hyperintensities to Alzheimer's disease. J Neurol Sci 1996;142: 121-125.

9 Awad IA, Johnson PC, Spetzler RF, Hodak JA: Incidental subcortical lesions identified on magnetic resonance imaging in the elderly. II. Postmortem pathological correlations. Stroke 1986;17:1090-1097.

10 DeCarli C, Murphy DGM, Tranh M, Grady CL, Haxby JV, Gillette JA, et al: The effect of white matter hyperintensity volume on brain structure, cognitive performance, and cerebral metabolism of glucose in 51 healthy adults. Neurology 1995;45:2077-2084.

11 Skoog I, Berg S, Johansson B, Palmertz B, Andreasson LA: The influence of white matter lesions on neuropsychological functioning in demented and non-demented 85-year-olds. Acta Neurol Scand 1996;93:142-148.

12 Ylikoski R, Ylikoski A, Erkinjuntti T, Sulkava $\mathrm{R}$, Raininko R, Tilvis R: White matter changes in healthy elderly persons correlate with attention and speed of mental processing. Arch Neurol 1993;50:818-824.
13 Almkvist O, Wahlund L-O, Andersson-Lundman G, Basun H, Bäckman L: White-matterhyperintensity and neuropsychological functions in dementia and healthy aging. Arch Neurol 1992;49:626-632.

14 de Groot JC, de Leeuw FE, Oudkerk M, Hofman A, Jolles J, Breteler MM: Cerebral white matter lesions and subjective cognitive dysfunction: The Rotterdam Scan Study. Neurology 2001;56:1539-1545.

15 Hunt AL, Orrison WW, Yeo RA, Haaland KY, Rhyne RL, Garry PJ, et al: Clinical significance of MRI white matter lesions in the elderly. Neurology 1989;39:1470-1474.

16 Wolf H, Ecke GM, Bettin S, Dietrich J, Gertz HJ: Do white matter changes contribute to the subsequent development of dementia in patients with mild cognitive impairment? A longitudinal study. Int J Geriatr Psychiatry 2000; 15:803-812.

17 Wu CC, Mungas D, Petkov CI, Eberling JL, Zrelak PA, Buonocore MH, et al: Brain structure and cognition in a community sample of elderly Latinos. Neurology 2002;59:383-391.

18 Hirono N, Kitagaki H, Kazui H, Hashimoto M, Mori E: Impact of white matter changes on clinical manifestation of Alzheimer's disease: A quantitative study. Stroke 2000;31:21822188.

19 Mungas D, Jagust WJ, Reed BR, Kramer JH, Weiner MW, Schuff N, et al: MRI predictors of cognition in subcortical ischemic vascular disease and Alzheimer's disease. Neurology 2001; 57:2229-2235.

20 Mungas D, Reed BR, Jagust WJ, DeCarli C, Mack WJ, Kramer JH, et al: Volumetric MRI predicts rate of cognitive decline related to $\mathrm{AD}$ and cerebrovascular disease. Neurology 2002; 59:867-873.

21 Van der Werf YD, Witter MP, Uylings HB, Jolles J: Neuropsychology of infarctions in the thalamus: A review. Neuropsychologia 2000; 38:613-627.

22 Mineura K, Sasajima H, Kikuchi K, Kowada M, Tomura N, Monma K, et al: White matter hyperintensity in neurologically asymptomatic subjects. Acta Neurol Scand 1995;92:151-156.

23 Moody DM, Bell MA, Challa VR: Features of the cerebral vascular pattern that predict vulnerability to perfusion or oxygenation deficiency: An anatomic study. AJNR Am J Neuroradiol 1990;11:431-439.

24 Ishii N, Nishihara Y, Imamura T: Why do frontal lobe symptoms predominate in vascular dementia with lacunes? Neurology 1986;36: 340-345.

25 Morris JH: Vascular dementia; in Esiri MM, Morris JH (eds): The Neuropathology of Dementia. Cambridge, Cambridge University Press, 1997, pp 137-171.

26 Yamanouchi H, Sugiura S, Tomonaga M: Decrease in nerve fibres in cerebral white matter in progressive subcortical vascular encephalopathy of Binswanger type. J Neurol 1989;236: 382-387.
27 McKhann G, Drachman D, Folstein M, Katzman R, Price D, Stadlan EM: Clinical diagnosis of Alzheimer's disease: Report of the NINCDS-ADRDA Work Group under the auspices of the Department of Health and Human Services Task Force on Alzheimer's disease. Neurology 1984;34:939-944.

28 Román GC, Tatemichi TK, Erkinjuntti T, Cummings JL, Masdeu JC, Garcia JH, et al: Vascular dementia: Diagnostic criteria for research studies. Report of the NINDS-AIREN International Workshop. Neurology 1993;43: 250-260.

29 Folstein MF, Folstein SE, McHugh PR: Minimental-state: A practical method for grading the cognitive state of patients for the clinician. J Psychiatr Res 1975;12:189-198.

30 Bokde AL, Teipel SJ, Zebuhr Y, Leinsinger G, Gootjes L, Schwarz R, et al: A new rapid landmark-based regional MRI segmentation method of the brain. J Neurol Sci 2002;194:35-40.

31 Woods RP, Grafton ST, Holmes CJ, Cherry SR, Mazziotta JC: Automated image registration. I. General methods and intrasubject, intramodality validation. J Comput Assist Tomogr 1998;22:141-154.

32 Morris JC, Heyman A, Mohs RC, Hughes JP, van Belle $G$, Fillenbaum $G$, et al: The Consortium to Establish a Registry for Alzheimer's Disease (CERAD). I. Clinical and neuropsychological assessment of Alzheimer's disease. Neurology 1989;39:1159-1165.

33 Rosen WG, Mohs RC, Davis KL: A new rating scale for Alzheimer's disease. Am J Psychiatry 1984;141:1356-1364.

34 Mantyla R, Erkinjuntti T, Salonen O, Aronen HJ, Peltonen T, Pohjasvaara T, et al: Variable agreement between visual rating scales for white matter hyperintensities on MRI: Comparison of 13 rating scales in a poststroke cohort. Stroke 1997;28:1614-1623.

35 Scheltens P, Erkinjunti T, Leys D, Wahlund LO, Inzitari D, del Ser T, et al: White matter changes on CT and MRI: An overview of visual rating scales. European Task Force on AgeRelated White Matter Changes. Eur Neurol 1998;39:80-89.

36 Scheltens P, Barkhof F, Leys D, Pruvo JP, Nauta JJP, Vermersch P, et al: A semiquantitative rating scale for the assessment of signal hyperintensities on magnetic resonance imaging. $\mathrm{J}$ Neurol Sci 1993;114:7-12.

37 Wahlund LO, Barkhof F, Fazekas F, Bronge L, Augustin M, Sjogren M, et al: A new rating scale for age-related white matter changes applicable to MRI and CT. Stroke 2001;32:13181322.

38 Jack CR Jr, O'Brien PC, Rettman DW, Shiung MM, Xu Y, Muthupillai R, et al: FLAIR histogram segmentation for measurement of leukoaraiosis volume. J Magn Reson Imaging 2001; 14:668-676.

39 Schmidt R: Comparison of magnetic resonance imaging in Alzheimer's disease, vascular dementia and normal aging. Eur Neurol 1992;32: 164-169. 
40 Scheltens P, Barkhof F, Valk J, Algra PR, van der Hoop GR, Nauta J, et al: White matter lesions on magnetic resonance imaging in clinically diagnosed Alzheimer's disease: Evidence for heterogeneity. Brain 1992;115:735-748.

41 Kawamura J, Meyer JS, Ichijo M, Kobari M, Terayama Y, Weathers S: Correlations of leuko-araiosis with cerebral atrophy and perfusion in elderly normal subjects and demented patients. J Neurol Neurosurg Psychiatry 1993;56: 182-187.

42 Shyu WC, Lin JC, Shen CC, Hsu YD, Lee CC, Shiah IS, et al: Vascular dementia of Binswanger's type: Clinical, neuroradiological and 99mTc-HMPAO SPET study. Eur J Nucl Med 1996;23:1338-1344.
43 Hanyu H, Imon Y, Sakurai H, Iwamoto T, Takasaki M, Shindo H, et al: Regional differences in diffusion abnormality in cerebral white matter lesions in patients with vascular dementia of the Binswanger type and Alzheimer's disease. Eur J Neurol 1999;6:195-203.

44 Brun A, Englund E: A white matter disorder in dementia of the Alzheimer type: A pathoanatomical study. Ann Neurol 1986;19:253-262.

45 Yamanouchi H, Sugiura S, Shimada H: Decrease of nerve fibres in the anterior corpus callosum of senile dementia of Alzheimer type. $\mathrm{J}$ Neurol 1989;236:491-492.

46 Villa G, Gainotti G, De Bonis C: Constructive disabilities in focal brain-damaged patients: Influence of hemispheric side, locus of lesion and coexistent mental deterioration. Neuropsychologia 1986;24:497-510.

47 Cohen RA, Paul RH, Ott BR, Moser DJ, Zawacki TM, Stone W, et al: The relationship of subcortical MRI hyperintensities and brain volume to cognitive function in vascular dementia. J Int Neuropsychol Soc 2002;8:743752 .
48 Teipel SJ, Hampel H, Alexander GE, Schapiro MB, Horwitz B, Teichberg D, et al: Dissociation between white matter pathology and corpus callosum atrophy in Alzheimer's disease. Neurology 1998;51:1381-1385.

49 Crowe SF: Dissociation of two frontal lobe syndromes by a test of verbal fluency. J Clin Exp Neuropsychol 1992;14:327-339.

50 Yamauchi H, Fukuyama H, Shio H: Corpus callosum atrophy in patients with leukoaraiosis may indicate global cognitive impairment. Stroke 2000;31:1515-1520.

51 Christiansen P, Larsson HB, Thomsen C, Wieslander SB, Henriksen O: Age dependent white matter lesions and brain volume changes in healthy volunteers. Acta Radiol 1994;35: 117-122. 